'Ilu. Revista de Ciencias de las Religiones

ISSN: $1135-4712$

http://dx.doi.org/10.5209/ILUR.57409

\title{
El tratamiento de la objeción de conciencia en el Consejo de Europa
}

\author{
Daniel Capodiferro Cubero ${ }^{1}$
}

Recibido: 9 de enero de 2017 / Aceptado: 15 de mayo de 2017

Resumen. En el seno del Consejo de Europa, la objeción de conciencia ha sido abordada esencialmente como un problema derivado de la colisión entre las convicciones propias de ciertos grupos religiosos minoritarios y el deber de prestar el servicio militar, si bien con el tiempo el fenómeno se ha ido secularizando y diversificando tanto en sus aspectos objetivos como subjetivos. A pesar de que el Tribunal Europeo de Derechos Humanos y los órganos políticos de la organización han mantenido aproximaciones notablemente distintas al respecto, en ambos casos se observa una clara, aunque lenta, evolución en sus planteamientos desde los años 60 hasta la actualidad, sobre todo en cuanto a la percepción de la naturaleza jurídica de la objeción de conciencia y su relación con la libertad de pensamiento, conciencia y religión del art. 9 del Convenio de Roma, hasta el punto de poder identificar a día de hoy una serie de puntos clave que dan forma a una línea doctrinal consistente. Con ello se ha abierto la posibilidad de su protección directa en los términos del mismo, lo que supone, en última instancia, la aparición de ciertos deberes para los Estados en lo que respecta a su reconocimiento o configuración.

Palabras clave: Objeción de conciencia; Libertad de pensamiento, conciencia y religión; Grupos religiosos minoritarios; Tribunal Europeo de Derechos Humanos; Consejo de Europa.

\section{[en] The treatment of conscientious objection in the Council of Europe}

\begin{abstract}
Within the Council of Europe, conscientious objection has been essentially addressed as a problem that results from the collision between the beliefs of minority religious groups and the duty of military service, although this issue has been secularised and diversified in both its objective and subjective aspects over time. Despite the differences between the approaches of European Court of Human Rights and the political bodies of the organization to the issue of conscientious objection, a clear, but slow, evolution can be observed from the 60's until today, especially regarding the perception of its legal nature and its relation with the freedom of thought, conscience and religion of the art. 9 of the Convention of Rome, showing today some key points that shape a consistent legal doctrine. This allows objectors to claim direct protection under the Treaty and imposes, ultimately, specific duties on states regarding the recognition of conscientious objection or the content of its regulatory framework.
\end{abstract}

Keywords: Conscientious objection; Freedom of thought, conscience and religion; Minority religious groups; European Court of Human Rights; Council of Europe.

Sumario. 1. Introducción. 2. La libertad de pensamiento, conciencia y religión en el CEDH. 3. La evolución de las declaraciones de los órganos políticos. 3.1. La objeción de conciencia al servicio militar. 3.2. La objeción de conciencia sanitaria. 4. La aproximación inicial del Tribunal Europeo de Derechos

1 Universidad Autónoma de Barcelona (España).

E-mail: daniel.capodiferro@uab.es 
Humanos. 5. La apertura a la protección indirecta de los objetores. 6. El cambio doctrinal y la subsunción de la objeción de conciencia en el art. 9 CEDH. 7. Los límites del derecho y la ponderación de intereses concurrentes. 8. Conclusiones. 9. Bibliografía.

Cómo citar: Capodiferro Cubero, D. (2017), El tratamiento de la objeción de conciencia en el Consejo de Europa, en 'Ilu. Revista de Ciencias de las Religiones 22, 71-96.

\section{Introducción}

La objeción de conciencia puede definirse como la reacción individual de un sujeto, derivada de la contradicción entre su conciencia y el contenido o fundamento de un deber jurídico que le afecta, que consiste en el incumplimiento del comportamiento estipulado por éste, acogiéndose a un deber que se plantea como alternativo o, en caso de que no se recoja tal posibilidad, pretendiendo la exención de responsabilidad jurídica por su conducta ${ }^{2}$. Quizá sea una de las cuestiones más delicadas a las que se enfrentan los sistemas jurídicos modernos ya que, en el fondo, lo que se plantea con ella es si existe alguna justificación lo bastante fuerte como para relajar, en ocasiones puntuales, su premisa nuclear: la obediencia de los ciudadanos a las normas, dando cobertura a demandas procedentes normalmente de miembros de grupos minoritarios que comparten ciertas premisas, por lo general de naturaleza religiosa (aunque no necesariamente) que no terminan de ser compatibles con la moral común positivizada. En caso afirmativo, la nueva cuestión que se suscita es en qué términos y mediante qué procedimientos se puede o se debe articular esta posibilidad para «reequilibrar» el sistema, canalizando a través del incumplimiento del mandato jurídico la protección de la dignidad personal de un determinado sujeto ${ }^{3}$.

El Consejo de Europa no ha sido ajeno a las controversias que implica este tema. Tanto la Asamblea consultiva y el Comité de Ministros como las distintas instancias del Tribunal Europeo de Derechos Humanos (TEDH) han abordado esta cuestión en diversos momentos centrándose, hasta fechas recientes, casi exclusivamente en una única manifestación de la misma: el rechazo por razones de conciencia a la realización del servicio de armas, primera en obtener un reconocimiento normativo en términos históricos por parte de los sistemas jurídicos nacionales $\mathrm{y}$, por mucho tiempo, la única que se concebía como posible 4 . Por ello, es la que más atención ha recibido en términos cuantitativos, constituyendo el supuesto base a partir del cual se ha construido la caracterización de este derecho.

2 Quedan fuera del objeto de este trabajo algunas cuestiones sobre las que existen pronunciamientos relevantes del Tribunal de Estrasburgo y que la doctrina ha venido considerando supuestos de objeción de conciencia, como puedan ser la oposición de los padres a que sus hijos cursen determinadas asignaturas incluidas en los programas educativos o la negativa a emplear determinadas fórmulas al realizar juramentos promisorios. El primer supuesto, además de tratarse de un problema relativo al derecho de los progenitores a escoger la formación moral o la educación de sus hijos, difícilmente podría calificarse como objeción de conciencia en la medida en que quien rechaza el deber no es el obligado por el mismo. En el segundo, lo que se da es una colisión directa con una de las dimensiones esenciales de la libertad ideológica y religiosa, como es el derecho a creer o a no creer y a manifestarlo.

3 Jerez Delgado y Madero Jiménez 2013, 176.

4 Oliver Araujo 1993, 46-47. De hecho, hasta finales de los años ochenta, la doctrina identificaba el derecho de objeción de conciencia únicamente con el supuesto relativo al servicio militar, sin concebir otras opciones. Baste ver como ejemplo del enfoque de los trabajos más clásicos la caracterización que realiza Cattelain 1973, 9ss, que agota el alcance objetivo de la objeción de conciencia en el deber de prestar el servicio militar. 
Justamente en este contexto, la objeción de conciencia resalta como un fenómeno social que emerge durante la década de los cincuenta y se consolida con particular intensidad a partir de los sesenta vinculado fuertemente a los planteamientos pacifis$\operatorname{tas}^{5}$, experimentado un procedimiento de secularización que, en la práctica, la ha ido alejando de su sustrato original exclusivamente religioso para encontrar justificación en razones de tipo humanístico o privadas ${ }^{6}$. A pesar de ello, las motivaciones de base religiosa no sólo no se han visto desplazadas como fundamento de los distintos casos de objeción de conciencia que han llegado al Tribunal de Estrasburgo, sino que son precisamente las que han fundamentado la mayor parte de las controversias que se analizarán a continuación hasta épocas más recientes. Así que se puede afirmar que, al menos en lo que respecta a la jurisprudencia del TEDH sobre el rechazo a los deberes militares, se trata de una cuestión fuertemente conectada con el problema del ejercicio externo de la libertad religiosa de los grupos minoritarios en las sociedades occidentales, aunque no se agota en ella y desde luego la supera en los últimos tiempos cuando los deberes son otros.

A este respecto, si bien se debe prestar atención a la actividad desarrollada tanto por los órganos de naturaleza política como jurisdiccional del Consejo de Europa, resulta imprescindible tener presente el alcance y las consecuencias de la actividad de cada uno. El carácter más político, más ideologizado si se prefiere, del Comité de Ministros y, en mucha mayor medida, de la Asamblea Parlamentaria condiciona necesariamente su trabajo y explica en buena medida las diferencias observables entre sus propuestas y las resoluciones del TEDH. Pero sobre todo, a efectos prácticos, es importante resaltar la distinta repercusión que, sobre el ordenamiento de los Estados miembros y la situación jurídica de sus ciudadanos, tendrán los pronunciamientos de cada uno. Tomando como ejemplo el caso español, el Tribunal Constitucional, a partir de la cláusula hermenéutica del art. 10.2 de la Constitución ${ }^{7}$, viene empleando sistemáticamente la jurisprudencia del TEDH como un criterio interpretativo privilegiado de los derechos reconocidos en la Norma Fundamental ${ }^{8}$, aunque nunca haya justificado teóricamente esta forma de proceder'. Por tanto, la doctrina elaborada por el Tribunal de Estrasburgo en relación a la objeción de conciencia debería servir como base para la posterior caracterización que de la misma realicen

5 Navarro Aznar 1990, 173ss. Sobre el contenido de las motivaciones éticas de la objeción de conciencia militar, se puede consultar Amérigo Cuervo-Arango 1985, 17ss. Y sobre la evolución histórica de la misma, Oliver Araujo 1993, 52ss.

6 Vid. Moskos y Chambers II 1993, 196.

7 Cuando este precepto establece que el deber de interpretar las normas relativas a los derechos fundamentales y a las libertades que la Constitución reconoce de conformidad con la DUDH y los tratados y acuerdos internacionales al respecto ratificados por España está convirtiendo a estos textos supranacionales en «parámetro determinante de la configuración de los derechos y libertades» en el ámbito interno (DTC 1/2004, de 13 de diciembre, $\mathrm{FJ}^{\circ}$ ), y, por extensión, también a los pronunciamientos de aquellos órganos de carácter jurisdiccional que tengan atribuida la competencia para interpretar sus disposiciones en la medida en que se les atribuye valor de cosa juzgada. Vid. López Guerra 2013, 142.

8 La primera ocasión en la que el Tribunal se remite a este criterio es la STC 22/1981, de 2 de julio, FJ $3^{\circ}$. Más explícita en su planteamiento es la STC 157/1993, de 6 de mayo, FJ 2º cuando señala que «los pronunciamientos de los órganos jurisdiccionales llamados a interpretar y aplicar los tratados y convenios internacionales suscritos por España en materia de derechos fundamentales y libertades públicas») resultan determinantes al fijar el contenido esencial de los derechos constitucionalmente reconocidos.

9 Sainz Arnaiz 1999, 167. Sobre las distintas formas en las que el Tribunal Constitucional ha empleado, a efectos interpretativos de los derechos fundamentales, la jurisprudencia de los tribunales internacionales, vid. pp. 241ss. 
en el nivel nacional tanto el Tribunal Constitucional como los Tribunales ordinarios, sin perjuicio de la posibilidad de que estos maticen o se alejen de aquella por razón de las peculiaridades del propio contexto ${ }^{10}$.

Por el contrario, el Tribunal Constitucional ha declarado no estar vinculado por las resoluciones del resto de órganos del Consejo de Europa. Así, «la interpretación relevante, de acuerdo con el art. 10.2 de la Constitución, es sólo la jurisdiccional del Tribunal Europeo, y no la del Comité de Ministros» ${ }^{11}$, como consecuencia del carácter político de éste ${ }^{12}$. La misma conclusión resulta extensible a la Asamblea Parlamentaria a la vista de su composición (conformada por representantes de los parlamentos de los Estados miembros) y su función básicamente deliberativa. Por tanto, hay que tener en cuenta que el valor de las resoluciones de ambos órganos queda reducido al de manifestaciones políticas que expresan el parecer mayoritario de los representantes de los Estados o simples recomendaciones para los miembros que en ningún caso son vinculantes para el poder público estatal ni producen efecto jurídico alguno sobre los particulares.

\section{La libertad de pensamiento, conciencia y religión en el CEDH}

Cuando el art. 9 CEDH consagra la libertad «de pensamiento, de conciencia y de religión» desglosa su contenido en «la libertad de cambiar de religión o de convicciones, así como la libertad de manifestar su religión o sus convicciones individual o colectivamente, en público o en privado, por medio del culto, la enseñanza, las prácticas y la observancia de los ritos» $\rangle^{13}$, sin mencionar en ningún momento la existencia de una concreta facultad para resultar liberado de una obligación jurídica por razón de las propias convicciones. Junto con ello, el apartado 2 del precepto plantea la posibilidad de limitar la manifestación de las propias convicciones cuando esté previsto por ley y sea necesario, en una sociedad democrática, para preservar «la seguridad pública, la protección del orden, de la salud o de la moral públicas, o la protección de los derechos o las libertades de los demás».

Se reconoce así un derecho a la «libertad de pensamiento» concebida en sentido integral, donde tienen cabida indistintamente las creencias de base religiosa o laica mientras sean auténticas, serias y estén especialmente arraigadas para el sujeto ${ }^{14}$. Con él se protege para éste la posibilidad de elegir o elaborar las respuestas que considere a todas las cuestiones que le plantea el devenir de su vida personal y social, de ajustar a esas respuestas sus actitudes y sus actos y de comunicar a los demás aquello que considera verdadero ${ }^{15}$. En esencia, la jurisprudencia de Estras-

\footnotetext{
López Guerra 2013,140.

STC 114/1984, de 29 de noviembre, FJ $3^{\circ}$.

Sainz Arnaiz 1999, 171.

Se trata de una fórmula amplia, que busca integrar las distintas aproximaciones constitucionales a este derecho, clara heredera del art. 18 de la Declaración Universal de los Derechos Humanos e inspiradora de textos más modernos como la Carta de los Derechos Fundamentales de la Unión Europea, cuyo art. 10 reitera en su primer apartado la caracterización del derecho, con el mismo sentido y alcance (es decir, con los mismos límites) que en el CEDH, al tiempo que, en el segundo, sí reconoce «el derecho a la objeción de conciencia de acuerdo con las leyes nacionales que regulen su ejercicio».

14 Xiol Ríos 2001, 17.

15 Vid. Rivero 1997, 152-153.
} 
burgo lo ha caracterizado como una libertad negativa de carácter individual, que protege contra la coacción pero difícilmente va a servir para reconocer prestaciones positivas $^{16}$.

Por otro lado, y dejando de momento al margen la objeción de conciencia, al enfrentarse a la libertad de pensamiento, conciencia y religión, el TEDH casi siempre se ha movido en planteamientos muy cautos, basados, salvo excepciones puntuales, en la concesión de un amplio margen de apreciación a los Estados para definir el alcance de sus límites, particularmente en lo que respecta a la exteriorización de manifestaciones de naturaleza religiosa ${ }^{17}$. De este modo, el mecanismo empleado para evaluar las posibles vulneraciones del derecho, consistente en un primer análisis sobre el encaje de la conducta problemática en el primer apartado del art. 9 CEDH seguido, en caso de respuesta afirmativa, por la valoración de la legitimidad de la restricción impuesta a partir de los parámetros del punto 2, acaba por relativizarse en la práctica, especialmente en lo referente a la aplicación de estos últimos.

El establecimiento previo por ley de la limitación, que equivale a la existencia de algún tipo de previsión normativa objetiva al respecto anterior al hecho, no plantea especiales problemas de aplicación para el Tribunal. Tampoco la cuestión de la finalidad legítima, respecto de la que suele tomar por buenos los argumentos que aportan los Estados ${ }^{18}$. Las mayores concesiones se dan en relación a la valoración de la necesidad y la proporcionalidad de la intervención limitativa, puesto que, con carácter general se asume que son los Estados quienes pueden apreciar mejor las exigencias que comporta la protección del interés público, y, correlativamente, interpretar su legislación interna en función de sus circunstancias particulares ${ }^{19}$. En este punto es donde el margen de apreciación estatal es más amplio, aunque no hasta el punto de otorgar una total discrecionalidad a los Estados, pues tal cosa llevaría a la ineficacia práctica del art. $9 \mathrm{CEDH}$. El Tribunal conserva cierta capacidad de control (cuestión distinta es que la ejerza) sobre las decisiones estatales, mayor cuanto más objetivables sean los bienes jurídicos que se contraponen a la libertad de pensamiento del sujeto o, especialmente, en aquellos casos en los que las limitaciones impuestas a este derecho afecten a una dimensión privada del mismo, sin repercusión externa o social ${ }^{20}$.

Estas consideraciones permiten explicar, en una primera aproximación, por qué la jurisprudencia de Estrasburgo ha sido particularmente reticente a amparar las demandas que, en casos de la más diversa naturaleza, han fundamentado sus pretensiones directamente en el art. $9 \mathrm{CEDH}$, al tiempo que se ha mostrado más abierta a considerar la existencia de vulneraciones cuando se invocaban otros derechos aunque el problema subyacente tuviera como base alguna manifestación de la libertad de pensamiento, conciencia y religión. La objeción de conciencia, como se irá viendo, no ha sido una excepción.

Arlettaz 2012, 235-236.

Arlettaz 2012, 225.

Arlettaz 2012, 227.

Martínez Torrón 2003, 15.

Martínez Torrón 2003, 16-17. 


\section{La evolución de las declaraciones de los órganos políticos}

\subsection{La objeción de conciencia al servicio militar}

La primera Resolución en la que la Asamblea Parlamentaria del Consejo de Europa manifestó su parecer sobre la objeción de conciencia al servicio militar fue la número 337 (1967), relativa al derecho a la objeción de conciencia ${ }^{21}$, cuya aproximación conceptual constituye la base teórica en la que se apoyará este órgano para todos sus pronunciamientos posteriores sobre el tema.

Resulta llamativo cómo desde el propio título ya se la califica como «derecho» (de carácter subjetivo además) para, inmediatamente, vincular el contenido de la Resolución con el art. 9 del Convenio y, en especial, con la «obligación de las partes contratantes de asegurar la libertad de religión y conciencia del individuo», ya que la objeción de conciencia "está considerada como derivación lógica de los derechos fundamentales del individuo» garantizados por dicho precepto en el ámbito de los Estados democráticos fundamentados en el principio de supremacía de la ley. La idea que se plantea, por tanto, es que la objeción de conciencia no es un fenómeno puramente social ni algo que pertenezca a la esfera privada del individuo, sino un mecanismo jurídico que responde a una facultad de base iusfundamental y permite a aquel hacer valer sus convicciones como causa de excepción frente a, en este caso, la obligación pública de prestar el servicio militar. A este respecto, se adopta un concepto amplio de conciencia individual, entendiendo que no sólo las convicciones de base religiosa, sino también las de orden «ético, moral, humanitario, filosófico o de naturaleza equiparable» pueden servir para invocar legítimamente el derecho a la objeción y, en última instancia, obtener el beneficio de la exención, siempre y cuando, eso sí, se trate de convicciones profundas o auténticos motivos de conciencia.

Por lo demás, la mayor parte del contenido del texto se centra en señalar algunas garantías básicas que deben ilustrar el procedimiento para la declaración de objetor, como que el sujeto debe ser informado de la posibilidad de objetar justo después de la primera notificación de inscripción en las listas o de la llamada a filas (Sección B, par. 1). También que la autoridad administrativa encargada de resolver las solicitudes de los candidatos a objetar no debe estar relacionada con la institución militar, garantizando en su composición la mayor independencia e imparcialidad posibles (par. 2), así como los derechos del demandante a ser escuchado, a estar asistido por un abogado y a recurrir a testigos (par. 5.). En conexión con esto, la posibilidad de recurso frente a decisiones desestimatorias se concibe como un elemento procedimental imprescindible (par. 3), ya sea ante instancias administrativas superiores u órganos judiciales independientes, respetando siempre las mismas garantías predicables de la primera instancia, sobre todo considerando que el rechazo a la prestación de armas podría llevar al pretendido objetor a enfrentarse a un proceso de tipo penal ${ }^{22}$. Finalmente, se recoge como una obligación para el Legislador nacional el estudiar cómo asegurar la eficacia del derecho mediante la suspensión de la incorporación a filas hasta la resolución de los procedimientos (par. 4).

\footnotetext{
Adoptada el 26 de enero de 1967, 22ª Sesión.

Vid. Rowe 2006, 20.
} 
En último término, la prestación sustitutoria se presenta como un elemento complementario de la objeción de conciencia en este supuesto. Desde la premisa de que este servicio alternativo no debe ser visto como un beneficio para el objetor, en el sentido de comportar una carga claramente menor, la Asamblea Parlamentaria planteó que su duración debía ser, al menos, la misma que la del servicio militar, garantizando la igualdad, en lo relativo a los aspectos económicos y de cobertura social, de los objetores en relación a quienes presten el servicio de armas. Como último punto, se señala que corresponde a los Gobiernos encargarse de que los objetores sean empleados en tareas de utilidad a la sociedad o a la colectividad, sin olvidar las múltiples necesidades de los países en vías de desarrollo.

Junto con esta Resolución, en la misma reunión, la Asamblea adoptó la Recomendación 478 (1967), sobre el derecho de objeción de conciencia al servicio militar, donde se invoca al Comité de ministros para la formulación de un Convenio o recomendación que lleve a los Estados miembros a reconocerlo en los términos más cercanos posibles a los principios mencionados. De manera muy similar se expresó la Asamblea Parlamentaria en el siguiente texto adoptado sobre este particular, la Recomendación 816 (1977), sobre el derecho de objeción de conciencia al servicio militar ${ }^{23}$. En ella, además de reproducir, literalmente, los principios de la Resolución 337, se urge a aquellos Gobiernos que no lo hayan hecho a acomodar su legislación a los mismos, además de, y esto es su principal novedad, proponer la incorporación del derecho de objeción de conciencia al articulado del CEDH, si bien únicamente referido al servicio militar.

La demandada intervención del Comité de Ministros no se produjo hasta 1987, mediante la Recomendación R (87) 8, sobre la objeción de conciencia al servicio militar obligatorio ${ }^{24}$. Si bien el texto está inspirado en los pronunciamientos previos de la Asamblea General, aboga por un tratamiento común de este supuesto en los Estados miembros desde un punto de vista más pragmático, suavizando algunas cuestiones importantes. Aunque reproduce esencialmente todo lo relativo a las garantías procedimentales o al status jurídico del objetor, introduce matices como el hecho de limitar la exigencia de no vinculación con el ámbito militar únicamente a la instancia de recurso (de la que sólo se predica su carácter administrativo) o no recoger expresamente el derecho a la asistencia letrada del demandante. Por otro lado, la Recomendación añade la opción, que no la obligación, de reconocer la posibilidad de objetar en conciencia de modo sobrevenido (par. 8), y define explícitamente la naturaleza de la prestación sustitutoria como no punitiva, asumiendo que la misma puede consistir también en un «servicio militar desarmado» destinado a los objetores cuyas convicciones se restrinjan al uso personal de armas (par. 9).

En cualquier caso, lo más llamativo de este texto es que renuncia a establecer un vínculo concreto entre la objeción de conciencia al servicio militar y cualquier artículo del CEDH; si bien en su justificación se habla de la deseable acción común para la mejor realización de los derechos humanos y las libertades fundamentales, la garantía del derecho de objeción de conciencia, que deja de calificarse como «subje-

Adoptada el 7 de octubre de 1977, 10ª Sesión.

Adoptada el 9 de abril de 1987 en la 406 Reunión del Comité de Ministros. La Asamblea Parlamentaria, mediante la Opinión 132, de 30 de enero de 1987 (28 Sesión), manifestó su aprobación a la citada Recomendación, si bien planteando algunos cambios de redacción, esencialmente en aquellas cuestiones en las que ésta se expresa en términos condicionales. 
tivo», se plantea como la solución a un problema social, como una cuestión práctica derivada de la vigencia de un deber que, en la mayor parte de los Estados miembros del Consejo de Europa, se erigía en ese momento como una obligación básica de los ciudadanos. De hecho, en ningún caso se define como una manifestación de la libertad de pensamiento, conciencia y religión, sin duda para evitar cuestionar las distintas leyes nacionales que, en cada caso, la reconociesen. Por el contrario, se adopta una perspectiva restrictiva ya superada no sólo por la Asamblea Parlamentaria, sino por las declaraciones de otros organismos internacionales ${ }^{25}$, donde la atención se focalizaba en enfatizar y poner en primer término la importancia de las garantías procedimentales.

Dejando de lado referencias puntuales al contenido de la Resolución 337 contenidas en textos que abordaban cuestiones $\operatorname{conexas}^{26}$, la objeción de conciencia al servicio militar no volvió a ser objeto de un pronunciamiento específico de la Asamblea Parlamentaria hasta la Recomendación 1518 (2001) ${ }^{27}$, titulada «Ejercicio del derecho de objeción de conciencia al servicio militar en los Estados miembros del Consejo de Europa». Este documento, último sobre la cuestión hasta la fecha, fue el resultado de un largo procedimiento que comenzó con una muy ambiciosa primera propuesta rechazada para su reformulación por parte de la Asamblea Parlamentaria en enero de $1993^{28}$. En ella, además de calificar abiertamente al derecho como de carácter fundamental, se insistía en su incorporación al articulado del CEDH, planteando la revisión de la Recomendación $\mathrm{R}$ (87) 8 para reafirmar la necesidad de una prestación sustitutoria netamente civil cuya duración no constituyera una sanción, así como para reivindicar una regulación racional tanto de la objeción de conciencia sobrevenida como de los casos en los que se plantee un «rechazo total» tanto del deber principal como del alternativo. Todo ello se acompañaba de una extensa justificación donde se contenía la formulación teórica más amplia sobre la objeción de conciencia que se había planteado hasta ese momento en el seno del Consejo de Europa, poniendo de manifiesto por primera vez su posible extensión (ya normativamente reconocida en algunos Estados) a otros supuestos más allá del servicio militar ${ }^{29}$.

25 Vid. Oliver Araujo 1993, 85.

26 Como en la Resolución 1166 de 1998, relativa a los Derechos Humanos de los reclutas, cuyo par. 9 establece que el derecho a la objeción de conciencia debe ser respetado de acuerdo a la Resolución 337 (1967) y la Recomendación $N^{o}$ R (87) 8. Sin embargo, la posterior Recomendación del Comité de Ministros N ${ }^{\circ} \mathrm{CM} / \mathrm{Rec}(2010) 4$, de 24 de febrero de 2010, sobre los Derechos Humanos de los miembros de las fuerzas armadas, sólo se remite a la Recomendación de 1987.

27 Adoptada el 23 de mayo de 2001por el Comité Permanente de la Asamblea.

28 Documento 6752, firmado por el diputado de la Izquierda Independiente M. Rodotà, y adoptado por la Comisión de Asuntos Legales y Derechos Humanos el 14 de diciembre de 1992.

29 En el memorándum explicativo de la propuesta la objeción de conciencia era concebida como una consecuencia necesaria del reconocimiento de la libertad de pensamiento y, por tanto, como un derecho «de alcance general que revela una incompatibilidad absoluta entre las convicciones personales y las reglas vigentes en una determinada comunidad» donde exista diversidad ideológica, ya que es vista como la única vía para «permitir la coexistencia de valores que, en otras circunstancias, estarian destinados a estar perpetuamente en conflicto», en lugar de concebirla como una excepción o una anomalía puntual. No obstante, como medida correctora para evitar que el reconocimiento incondicional de la objeción de conciencia por el que parece abogarse acabe suponiendo un perjuicio directo sobre los derechos de otros ciudadanos, se reivindicaba en última instancia el respeto al principio de legalidad, entendiendo que todo supuesto distinto del relativo al servicio militar necesita de un reconocimiento previo para poder ser aceptado por el Ordenamiento. El resultado de la argumentación era que la objeción de conciencia al servicio militar, y sólo ésta, acababa resultando privilegiada como parte del contenido esencial de la libertad de pensamiento, aunque no se aportara realmente ninguna razón de fondo, más allá de su recorrido histórico, para justificarlo. 
La cuestión no se retomó hasta la propuesta de recomendación de 4 de mayo de $2001^{30}$, cuyo memorándum explicativo renuncia a elaborar teoría alguna sobre la naturaleza de la objeción de conciencia y se limita a justificar la pertinencia del texto a partir de los pronunciamientos anteriores de los órganos políticos y jurisdiccionales del Consejo de Europea y de la valoración de las diversas soluciones que, para cada situación, han sido adoptadas por los distintos Ordenamientos europeos. Aun así, se contienen algunas afirmaciones relevantes en relación a la jurisprudencia: se reconoce que la existencia de un servicio militar obligatorio no contradice, en sí misma, el art. 9 CEDH (par. 14), y que, si bien «el derecho a la objeción de conciencia puede no estar garantizado por el art. 9 CEDH», debería ser reconocido más ampliamente, permitiendo recurrir a él tanto a los reclutas como a los militares profesionales en cualquier momento del servicio, dado que se trata «de hecho, de un aspecto fundamental del derecho a la libertad de pensamiento, conciencia y religión» consagrado por la DUDH y el CEDH (par. 15).

El resultado final, la Recomendación 1518 (2001), es un texto continuista con los trabajos previos, si bien adopta una visión más funcional y reduce los niveles de exigencia sobre los Estados miembros. La objeción de conciencia pasa de concebirse como una «consecuencia lógica» de la libertad de pensamiento, conciencia y religión a ser tratada como un fenómeno integrable en este derecho que debe ser reconocido por los sistemas jurídicos nacionales, marcando unos mínimos con el fin de armonizar las considerables diferencias existentes entre países. Para ello, la Recomendación se centra en algo tan básico como reivindicar la posibilidad efectiva de objetar en cualquier momento y para cualquier sujeto, vinculado de modo temporal o permanente a las Fuerzas Armadas, que debe poder acceder a información al respecto. Se obvia cualquier referencia a las garantías procedimentales sobre las que tanto énfasis pusieron los textos anteriores, y ello a pesar de reconocer que la situación de los objetores es «totalmente insatisfactoria en los Estados miembros que han reconocido el derecho». En cualquier caso, se reitera nuevamente la conveniencia de implementar una prestación sustitutoria de carácter civil no disuasoria ni punitiva, así como la recomendación de incorporar el derecho de objeción de conciencia al servicio militar en el art. $9 \mathrm{CEDH}$, opciones ambas discutidas ulteriormente por el Comité de Ministros, que afirmó que no existía necesidad alguna de actualizar su Recomendación de $1987^{31}$.

\subsection{La objeción de conciencia sanitaria}

El interés de la Asamblea Parlamentaria del Consejo de Europa por la objeción de conciencia en el ámbito sanitario, eminentemente referida al supuesto del aborto, es mucho más reciente. Se limita a una única resolución que, si bien en su plantea-

30 Documento 8809, «Ejercicio del derecho de objeción de conciencia al servicio militar en los Estados miembros del consejo de Europa», firmado por el diputado D. Marty, del Grupo de los Liberales, Demócratas y Reformistas, y adoptado por la Comisión de Asuntos Legales y Derechos Humanos el 13 de junio de 2000.

31 En su respuesta, adoptada en la 785ª Reunión de 26-27 de febrero de 2002 (documento 9379, de 1 de marzo de 2002), el Comité de ministros rechazó la necesidad de introducir la objeción de conciencia al servicio militar en el CEDH, considerando preferible realizar un esfuerzo para implementar de manera efectiva su Recomendación de 1987. Además, defendió la legitimidad una prestación sustitutoria de mayor duración que el servicio militar dado su carácter menos oneroso, entendiendo que, en última instancia, los Estados deben gozar de cierta capacidad discrecional para determinar libremente el tiempo y la organización de la misma. 
miento general puede entenderse alineada con los pronunciamientos acerca de la objección al servicio militar en la medida en que contiene una visión muy benevolente y aboga por maximizar el alcance del derecho, resulta contradictoria con otros textos previos ${ }^{32}$; y desde luego, es sorprendentemente vaga y poco realista.

El primer documento de trabajo al respecto es una propuesta de resolución de $2008^{33}$, donde se alertó de los graves riesgos que para la salud de las mujeres, particularmente en áreas rurales, implica la ausencia de «un marco legal y político integral y efectivo que ordene el recurso a la objeción de conciencia por parte de los empleados de los servicios de salud» en los Estados miembros. Al tiempo que se planteaba reconocer la posibilidad de objetar en conciencia a ciertos tratamientos médicos por parte de los individuos o las instituciones a partir de razones religiosas, morales o filosóficas, se decía que los Estados deberían regular y ordenar este fenómeno con el fin de que las mujeres puedan «acceder a los servicios médicos que necesitan y tienen legalmente reconocidos», en clara referencia a la interrupción del embarazo; la finalidad sería asegurar que su remisión a profesionales no objetores de cualificación equivalente, y localizados a una distancia razonable, se realice en el plazo debido. Finalmente, se insiste en que no se debe contemplar la posibilidad de que los centros públicos recurran a la objeción como instituciones en su conjunto, todo con la finalidad de que los derechos de los profesionales no se acaben imponiendo a los de las mujeres, negando, en última instancia, la eficacia a su decisión.

A partir de esta primera iniciativa, la Comisión de Asuntos Sociales, Salud y Familia aprobó, en junio de 2010, una doble propuesta de resolución y recomendación ${ }^{34}$. En la primera, tras considerar el insatisfactorio tratamiento normativo de este supuesto por parte de las legislaciones estatales y la necesidad de asegurar tanto los derechos de los pacientes como la libertad de pensamiento de los facultativos, se invita a los Estados a restringir el recurso a la objeción de conciencia a los profesionales individuales directamente implicados en el procedimiento en cuestión, que nunca se verían liberados del deber de informar a los pacientes de todas las alternativas de tratamiento posibles (incluso las que supongan conflictos morales). Además, se menciona la necesidad de responsabilizar a los objetores de remitir a los pacientes en plazo a otro facultativo y asegurarse de que allí reciben el tratamiento adecuado, así como de limitar la objeción de conciencia en casos de emergencia o cuando dicha remisión no pueda realizarse en términos razonables. Junto con esto, se entiende que es misión de los Estados vigilar y controlar la objeción de conciencia para «asegurar que todos, y especialmente las mujeres, tienen acceso a un tratamiento efectivo y en el tiempo debido», lo que incluye la implementación de procedimientos de reclamación efectivos.

A pesar de todo, el resultado final del procedimiento acabó distando mucho de todo lo expuesto. En una votación polémica y por una muy escasa diferencia ${ }^{35}$, se

32 Básicamente la Resolución 1607 (2008), de 16 de abril, donde se invitaba a los Estados a garantizar el ejercicio efectivo del derecho de las mujeres a acceder a un aborto sin riesgos y legal, respetando su libertad de elección y eliminando las restricciones que, de hecho o de derecho, lo impidieran.

33 Documento 11757, Propuesta de Resolución de 14 de octubre de 2008, firmada por 21 parlamentarios, titulada «El acceso de las mujeres a los tratamientos médicos legales: el problema del uso desregulado de la objeción de conciencia».

34 Documento 12347 , de 10 de julio de 2010, con el mismo título que la primera propuesta, firmado por la diputada C. McCafferty, del Grupo Socialista.

35 Resulta llamativo como, a consecuencia del momento en el que se emplazó la votación del texto (última hora del jueves), sólo 111 de los 318 miembros de la Asamblea Parlamentaria estuvieron presentes en la misma, aprobándose la versión definitiva del texto por 56 votos a favor frente a 51 en contra, con 4 abstenciones. 
aprobó la Resolución 1763 (2010), de 7 de octubre, titulada «El derecho de objeción de conciencia en los tratamientos médicos», donde la garantía de los derechos de la mujer, premisa básica de los trabajos previos, resulta totalmente obviada para focalizar la atención en la figura de los objetores. Con una redacción pretendidamente ambigua y llena de lagunas y omisiones, la Resolución comienza declarando que ninguna persona, hospital o institución serán coaccionados, responsabilizados o discriminados de modo alguno por negarse a llevar a cabo, permitir, asistir o prescribir un aborto, llevar a cabo una eutanasia o realizar cualquier acto que suponga la muerte de un feto o embrión humano, sin importar la razón por la que se haga. Esto supone, ya como partida, desnaturalizar la objeción de conciencia al obviar cualquier referencia a la seriedad de las convicciones que la motivan, además de ampliar injustificadamente su titularidad a las personas jurídicas.

A diferencia de los textos sobre la objeción militar, el documento final de la Asamblea omite cualquier referencia sobre la fundamentación del derecho en este supuesto o su relación con el CEDH, variando el discurso precedente sobre la legitimidad de la actuación del objetor. Se centra en enfatizar su vigencia sin prestar atención a posibles causas o conflictos que sugieran la restricción de su alcance ni al debido equilibrio con los derechos de la mujer. Así, se plantea responsabilizar íntegramente a los a los Estados de asegurar que éstas pueden acceder en plazo al tratamiento demandado, invitándoles a regular la objeción de conciencia de manera que se garantice que los profesionales podrán invocarla en relación a cualquier procedimiento médico, sin requisito alguno o deber complementario. Como contrapartida, los derechos de los pacientes se reducen a ser informados a tiempo de la objeción para ser remitidos a otro profesional y a recibir tratamiento adecuado en casos de emergencia, lo que supone desconectar el fenómeno de la objeción de conciencia en este ámbito no sólo del art. $9 \mathrm{CEDH}$, sino de cualquier otro que asegure los derechos de los demás.

\section{La aproximación inicial del Tribunal Europeo de Derechos Humanos}

Desde 1966, momento del primer pronunciamiento de la extinta Comisión Europea de Derechos Humanos, hasta fechas recientes se podría decir que, en términos globales, los órganos jurisdiccionales del Consejo de Europa han mostrado relativamente poco interés en proteger a los objetores de conciencia al servicio militar, en buena medida a causa de la falta de cobertura expresa de este derecho en el $\mathrm{CEDH}^{36}$. No obstante, se puede apreciar una progresiva, aunque muy lenta, evolución de la doctrina, que no sólo ha abandonado la postura restrictiva inicial, sino que ha aceptado la integración de este derecho en el Convenio de Roma. En cualquier caso, se trata de un proceso de apertura que aparece como ajeno e independiente a la línea que han ido marcando en el tiempo los órganos políticos de la organización, evidenciando una notable falta de diálogo e influencia entre ambas instancias, al menos en esta cuestión.

La primera fase de este iter se caracteriza por el rechazo sistemático, por parte de la Comisión Europea de Derechos Humanos, de toda demanda que invocara la

36 Navarro Valls y Martínez Torrón 2012, 97. 
lesión de un derecho a la objeción de conciencia, argumentando que una conducta así estaba excluida del ámbito de protección del Convenio de Roma. Así se evitaba entrar a valorar las distintas legislaciones estatales. De ahí que se haya afirmado que la jurisprudencia de Estrasburgo acabó, en la práctica de este primer momento, por reducir el ámbito de protección del art. 9.1 CEDH en lugar de interpretar restrictivamente sus límites ${ }^{37}$.

El fundamento de esta postura se definió en la Decisión del caso Grandrath c. Alemania, de $1966^{38}$. En esencia, el Tribunal entendió que a la luz del CEDH, una reclamación relativa a la objeción de conciencia militar sólo podía ser valorada a partir del art. 4.3.b), donde se excluye de la definición de «trabajo forzado u obligatorio» todo «servicio de carácter militar o, en el caso de objetores de conciencia en los países en que la objeción de conciencia sea reconocida como legítima, cualquier otro servicio sustitutivo del servicio militar obligatorio». A partir de una interpretación literal de este precepto y teniendo en cuenta que en el caso concreto no se reclamaba directamente el reconocimiento de la exención al servicio militar ${ }^{39}$, el TEDH entendió que su invocación no sirve para eximir a un sujeto de la prestación sustitutoria que establezca cada Estado (par. 32), aunque, eventualmente, el conflicto pudiera ser analizado desde la óptica del principio de igualdad del art. 14 en caso de diferencias de trato injustificadas en el acceso a dicho beneficio. Así, si bien no se niega de modo directo la posible existencia de un derecho a la objeción de conciencia en el ámbito militar, sí que se da a entender que el Convenio no obliga a los Estados a reconocerlo ni impone unos términos concretos para ello, ya que se descarta que pueda existir conexión alguna entre el mismo y el art. 9 CEDH. Por tanto, la libertad de pensamiento, conciencia y religión no resulta vulnerada por obligar a un sujeto a prestar el servicio de armas en contra de sus convicciones religiosas (par. 33), diciendo simplemente que toda interpretación de los términos de este precepto en relación al caso resulta «superflua».

No obstante, en este primer momento es posible encontrar algún llamativo titubeo argumental de la Comisión, como en el fundamento de la Decisión $X$ contra Holand ${ }^{40}$, donde sí se recurre al art. 9.2 CEDH para valorar un caso de objeción de conciencia ante el deber de contar con un seguro obligatorio de vehículos. Aunque en última instancia la demanda es igualmente inadmitida, el fallo asume expresamente la vinculación de la pretensión con la libertad de manifestar las propias convicciones, y trata el problema desde el punto de vista de la legitimidad de su limitación: se concluye que el Estado está legitimado para no permitir excepciones a la obligación en cuestión porque ésta sirve para «proteger los derechos de terceros que puedan ser víctimas de accidentes de motor»». En consecuencia, en una situación así puede limitar válidamente la libertad de pensamiento de sus ciudadanos por resultar necesario en una sociedad democrática para asegurar los derechos y libertades de los demás.

En cualquier caso, esta línea no tuvo continuidad, y las Decisiones posteriores fueron consolidando la idea de la objeción de conciencia como una materia que excedía los límites del CEDH para caer plenamente en la discrecionalidad estatal.

\footnotetext{
Martínez Torrón 2003, 9-10.

Grandrath c. Alemania, n 2299/64, Decisión de la Comisión de 12 de diciembre de 1966.

Brett y Townhead 2011, 93.

X. c. Holanda, $\mathrm{n}^{\circ}$ 2988/66, Decisión de la Comisión de 31 de mayo de 1967.
} 
Más que de la concesión de un amplio margen de apreciación a los Estados, en este momento parece más adecuado hablar de incompetencia asumida y declarada de la Comisión para juzgar este tipo de cuestiones, ya que no se está concediendo la posibilidad de modular el alcance de un precepto del Convenio en función de las particularidades nacionales, sino excluyendo su aplicabilidad sobre un determinado fenómeno. Así, en G.Z. c. Austria ${ }^{41}$, la Comisión negó expresamente que el art. 9 CEDH imponga obligación alguna a los Estados parte de «reconocer a los objetores de conciencia y, en consecuencia, a adoptar disposiciones especiales para el ejercicio de su derecho a la libertad de conciencia y religión en la medida en que afecte al servicio militar obligatorio», lo que incluye la posibilidad de castigar a quienes lo rechacen si no hay exención normativamente prevista, circunstancia extensible a la prestación sustitutoria en caso de ser obligatoria ${ }^{42}$. Lo mismo se dijo en relación a la objeción fiscal en C. c. Reino Unido, de $1983^{43}$, donde además se hizo hincapié en que la falta de orientación moral de las normas tributarias impedía el surgimiento de un auténtico conflicto de conciencia.

La amplia discrecionalidad concedida a los Estados llegaba hasta el punto de aceptar que el Legislador nacional pudiera variar las consecuencias de la invocación de la objeción de conciencia en función de la naturaleza de las convicciones alegadas. En el caso N. c. Suecia, de $1984^{44}$, se da por bueno que la norma nacional limite el acceso al beneficio de la exención frente al servicio de armas a quienes aleguen convicciones de tipo religioso, rechazando las de carácter ético (pacifista en este caso). A juicio de la Comisión, concurría una justificación objetiva y razonable a la luz del art. $14 \mathrm{CEDH}$ : en la medida en que el servicio militar constituye una pesada carga para los ciudadanos, sólo será aceptable «si se comparte de manera equitativa» y si las excepciones al mismo «están basadas en fundamentos sólidos》 como pueden ser, se apunta, las genuinas convicciones religiosas, que no se consideran en este punto equiparables con las de aquellos sujetos que no sean miembros de una comunidad que no tenga tal naturaleza. Todo ello con el fin de que los Estados puedan «evitar el riesgo de que los individuos que simplemente quieren librarse del servicio lo puedan hacer pretendiendo objetar en conciencia contra cualquier servicio obligatorio en general» sin que exista un verdadero conflicto de conciencia, razón que, además, legitimaba a las autoridades nacionales para exigir a los ciudadanos una prueba particular de la seriedad de sus convicciones religiosas.

Por último, se puede reseñar el caso Crespo Azorín c. España, de 199045, donde se planteó, en abstracto, la compatibilidad de tres previsiones de la legislación española entonces vigente (el hecho de que el Consejo Nacional de Objeción de Conciencia pudiera investigar sobre la seriedad de las convicciones alegadas, la imposibilidad de plantear la objeción de conciencia tras la incorporación a filas y la mayor dura-

41 G.Z. c. Austria, no 5591/72, Decisión de la Comisión de 2 de abril de 1973. En los mismos términos se expresó la Comisión en el caso Objetores de conciencia c. Dinamarca, n 7565/76, Decisión de 7 de marzo de 1977.

42 Vid., por poner dos ejemplos de los muchos que existen, Xc. Alemania, $\mathrm{n}^{\mathrm{0}} 7705 / 76$, Decisión de la Comisión de 5 de julio de 1977, o Johansen c. Noruega, $\mathrm{n}^{\circ}$ 10600/83, Decisión de la Comisión de 10 de octubre de 1985, donde se reitera que, a partir del art. $9 \mathrm{CEDH}$, no existe un derecho de los objetores a ser eximido de la prestación sustitutoria, por lo que los Estados pueden tanto imponerla como obligatoria como sancionar a quienes se opongan a su cumplimiento.

43 C. c. Reino Unido, $\mathrm{n}^{\circ}$ 10358/83, Decisión de la Comisión de 15 de diciembre de 1983

44 N. c. Suecia n $^{\circ}$ 10410/83, Decisión de la Comisión de 11 de octubre de 1984.

45 Crespo Azorín c. España, no 13872/88, Decisión de la Comisión de 17 de mayo de 1990. 
ción de la prestación sustitutoria en relación al servicio militar) con los arts. 9 y 14 CEDH. Tras declarar que el hecho de tener que solicitar a un órgano administrativo la concesión del estatuto de objetor no constituye injerencia alguna en los derechos a la vida privada o a la libertad de pensamiento, la Comisión rehusó entrar a valorar las vulneraciones alegadas en la medida en que ninguna de las normas citadas fue aplicada directamente al recurrente. Tampoco resolvió, en última instancia, las dudas sobre la existencia de una hipotética discriminación por razón de género en la imposición del servicio militar sólo a los varones, reiterando que, al no estar reconocida en el CEDH, la objeción de conciencia no era un asunto de su competencia.

\section{La apertura a la protección indirecta de los objetores}

El inicio de la segunda etapa, que prácticamente coincide con la desaparición de la Comisión de Derechos Humanos, está inevitablemente ligado al cambio de tendencia en relación a la protección de la dimensión externa de la libertad religiosa que supuso el fallo Kokkinakis c. Grecia ${ }^{46}$, donde se consideró que la condena impuesta a un sujeto por llevar a cabo actos de proselitismo religioso vulneraba de modo directo el art. 9 CEDH. En esta fase, el Tribunal de Estrasburgo comenzó a dar respuesta afirmativa a demandas sobre cuestiones puntuales relacionadas con el rechazo al servicio militar que, en casi todas las ocasiones, procedían de Testigos de Jehová sancionados por oponerse a su incorporación a filas. Por primera vez, se cuestionaban los límites de las capacidades estatales en relación a la configuración de este deber. Pero se hizo sin admitir que dentro de la libertad de pensamiento, conciencia y religión, tal y como se consagra en el art. 9 del Convenio, pudiera entenderse implícito un derecho a la objeción de conciencia ${ }^{47}$. De hecho, todos los fallos de esta época tienen en común que eluden valorar las demandas a partir de este precepto considerado individualmente, empleándolo siempre en conexión con otros artículos, frecuentemente la prohibición de discriminación; o, simplemente, acudiendo a otros derechos para resolver. Así, al mismo tiempo que se evitaba una cuestión problemática $^{48}$, se justificaban unos fallos con un importante componente casuístico que, en la práctica, escenificaban el abandono de la doctrina inicial de la Comisión, aunque ésta nunca fuera formalmente modificada ${ }^{49}$.

Si ésta era la postura en relación al rechazo al servicio militar, resulta obvio que mucho menos se daría cobertura directa a otros supuestos de objeción de conciencia donde las diferencias en cuanto a su reconocimiento eran mayores en términos comparados. El ejemplo más claro, relativo al ámbito farmacéutico, es la decisión de inadmisión del asunto Pichon y Sajous c. Francia ${ }^{50}$, que recuerda la tónica de la etapa anterior al tiempo que en ella subyace cierta idea de ponderar los intereses presentes en el caso. Recordando que el art. $9 \mathrm{CEDH}$ «no siempre garantiza el derecho a comportarse en público del modo que dictan» las propias convicciones y que el término «práctica» empleado por este precepto no abarca cualquier acto o forma de

\footnotetext{
Kokkinakis c. Grecia, no 14307/88, 25 de mayo de 1993.

Cañamares Arribas 2014, 44.

Ruiz Bursón 2013, 7.

Navarro Valls y Martínez Torrón 2012, 99

Pichon y Sajous c. Francia (Dec.), nº 49853/99, 2 de octubre de 2001.
} 
comportamiento motivado o inspirado por una religión o una creencia, el Tribunal concluyó aquí que los demandantes, al negarse a vender medicamentos contraceptivos que sólo pueden ser dispensados en farmacias, estaban anteponiendo e imponiendo sus creencias religiosas a los demás, existiendo otras formas fuera del ámbito profesional para manifestarlas (que, habría que añadir, no entraban en colisión con los derechos de los demás). Por ello, su pretensión no resultaba aceptable.

Cronológicamente, el fallo que inicia el cambio de tendencia es la Sentencia del caso Tsirlis y Kouloumpas c. Grecia, de $1997^{51}$, donde, por otro lado, no se plantea explícitamente un caso de objeción de conciencia, sino una cuestión aparentemente tangencial. El Tribunal apreció una vulneración del art. 5.1 CEDH (derecho a la libertad y a la seguridad personal y prohibición de detenciones irregulares) por el encarcelamiento de dos ministros de culto acusados de insubordinación al negarse a llevar el uniforme militar. Ambos sujetos pertenecían a una confesión que había sido reconocida por las autoridades nacionales al mismo nivel que otras a cuyos representantes se eximía de la prestación del servicio militar. Lo que la Sala concluye es que existió una aplicación incorrecta de las propias normas por parte de las autoridades nacionales que llevó a una detención arbitraria y, por ello, merecedora de amparo bajo el Convenio. La cuestión de la adscripción religiosa de los demandantes o el motivo de la detención realmente tienen una importancia secundaria en la motivación del fallo aunque, en la práctica, la decisión adoptada protege indirectamente la libertad de culto de los condenados.

El Tribunal no discute la libertad del Estado para establecer las condiciones para acceder al beneficio de la objeción, sino cómo ha actuado el poder público al llevarlas a la práctica, por lo que, quizá, la no incorporación del art. 9 CEDH al núcleo del razonamiento sí está justificada. Por otro lado, los recurrentes no ligan la posible vulneración de este precepto al hecho de que se les sancione por no querer incorporarse a filas, sino a la circunstancia de que la privación de libertad que sufren les impide realizar su labor como ministros de culto, por lo que la cuestión del encaje de la objeción de conciencia en el Convenio sólo se plantea de modo indirecto. Aun así la Sala, pese a reconocer que «la detención de los demandantes a la espera de la decisión administrativa respecto a su demanda de exención del servicio militar se encuentra en el origen de las denuncias» a partir de los arts. 9 y $14 \mathrm{CEDH}$, elude pronunciarse al respecto al haber apreciado ya la vulneración de otro derecho fundamental.

La condición de objetor también está en el origen de una vulneración de derechos distintos a la libertad de pensamiento, conciencia y religión en el fallo Raninen $c$. Finlandia $^{52}$. Sólo que en este caso, el demandante no alegó vulneración del art. 9 $\mathrm{CEDH}$, sino de la prohibición de tratos degradantes. Pero aun así, y al igual que en la sentencia anterior, el hecho de que las actuaciones en las que se produjo la lesión del derecho fueran consecuencia del rechazo del demandante a prestar el servicio militar resulta totalmente irrelevante en la valoración del Tribunal, que no considera las razones de conciencia subyacentes como un elemento a tener en cuenta para ponderar la gravedad de una determinada actuación del poder público cuando afecta a otro derecho. A la vista de ambos fallos se puede decir que, en este momento, el modo de proceder del Tribunal se sistematiza en la siguiente máxima: una vez deci-

51 Tsirlis y Kouloumpas c. Grecia, no 19233/91 y 19234/91, 29 de mayo de 1997. La primera de las demandas acumuladas fue admitida parcialmente a trámite por la Comisión mediante Decisión de 4 de septiembre de 1995.

52 Raninen c. Finlandia, no 20972/92, 16 de diciembre de 1997. 
dido que la pretensión del demandante debe ser amparada, cualquier otro derecho cuya aplicación sea menos problemática, o políticamente comprometida, resulta preferible como sustento argumental de los fallos antes que la libertad de pensamiento, conciencia y religión.

La primera ocasión en la que el TEDH emplea abiertamente los arts. 9 y 14 en relación a la objeción de conciencia es en el fallo Thlimmenos c. Grecia, de $2000^{53}$. Y no lo hace para reconocer un derecho a la exención del servicio militar por motivos de conciencia, sino para remediar una situación de discriminación sufrida por un objetor condenado por negarse a realizarlo en el pasado a partir de motivaciones de tipo religioso. De hecho, se descarta, sin mayor razón, entrar a valorar la existencia de una lesión directa de la libertad de pensamiento, conciencia y religión del demandante, aunque éste solicitó la revisión de la doctrina elaborada por la Comisión en relación a la objeción de conciencia «a la luz de las condiciones presentes» (par. 50-53). El problema se aborda como un caso en el que no concurre una «objetiva y razonable justificación para no tratar al demandante de manera diferente a otras personas condenadas por crimenes graves» (par. 47). De hecho, si en la sentencia no hubiera referencias al art. $9 \mathrm{CEDH}$, se podría pensar que la vulneración del principio de igualdad que se imputa a la ley nacional sólo se debe al hecho de impedir el acceso a un determinado puesto público a sujetos condenados por delitos que en nada prejuzgan la aptitud para su desempeño. Pero al imbricar la libertad de pensamiento en su razonamiento, el Tribunal vincula la noción de «castigo desproporcionado» a la especial motivación que llevó al sujeto a realizar la conducta por la que fue castigado (la negativa a incorporarse a filas). De este modo se viene a afirmar, a través de la implementación del principio de igualdad como prohibición de tratar del mismo modo casos diferentes, que la negativa, por razones religiosas o morales, a prestar el servicio militar no puede justificar discriminación o represalia ulterior alguna, con lo que se está sugiriendo, indirectamente, cierta injusticia en el castigo original.

Si bien en esta sentencia sigue sin cuestionarse, en términos de legitimidad o idoneidad, la libertad de los Estados sobre la regulación de la objeción de conciencia, esta postura parece variar poco después en el fallo Ülke c. Turquí $a^{54}$, donde se aprecia una evolución de la doctrina del Tribunal en relación al juicio de proporcionalidad ${ }^{55}$, además de no excluir tajantemente la eventual aplicabilidad del art $9 \mathrm{CEDH}$. Por primera vez, se limita el margen de acción que el CEDH reconoce a los Estados para establecer las consecuencias jurídicas de la negativa en conciencia a cumplir con el servicio militar ${ }^{56}$, concluyendo que la posibilidad de castigar de manera reiterada con penas de prisión al sujeto cada vez que se niega a incorporarse a filas (dado que la condena no le libera de la obligación de armas) que permite la legislación turca constituye un trato degradante en los términos del art. 3 CEDH a causa de su gravedad y naturaleza reiterativa (par. 63), además de por las consecuencias que puede suponer para el resto de su vida (par. 62). Al denunciar que el marco legal nacional «resulta evidentemente insuficiente para abordar de manera adecuada las situaciones que surgen del rechazo a cumplir con el servicio militar a causa de las propias creencias» (par. 61), y, por tanto, inadecuado, el Tribunal está considerando el grado

\footnotetext{
Thlimmenos c. Grecia [GS], no 34369/97, 6 de abril de 2000.

Ülke c. Turquía, no 39437/98, 24 de abril de 2006.

Brett y Townhead 2011, 96.

Navarro Valls y Martínez Torrón 2012, 102.
} 
de desvalor que debe merecer para el Derecho Penal esta conducta desde el punto de vista de lo aceptable según el Convenio, concluyendo que es bajo (o, en otras palabras, que no es un acto demasiado ilegítimo) y, por tanto, no puede llevar aparejado un castigo grave, especialmente porque, aunque no se emplea el art. $9 \mathrm{CEDH}$ en el razonamiento, sí se viene a reconocer que existe una conexión causal entre la "personalidad intelectual» (las creencias) del demandante y su actuación reiterada ${ }^{57}$.

Ya en 2009, las sentencias de los casos Löffelmann c. Austria, Gütl c. Austria y Lang c. Austria ${ }^{58}$, consolidaron la doctrina de 1997 sobre la prohibición de discriminación entre miembros de distintas confesiones religiosas, aplicándola en esta ocasión al acceso a la condición de objetor. A diferencia del fallo Tsirlis, aquí se recurre a los arts. 14 y $9 \mathrm{CEDH}$ de manera conjunta para concluir que, en cada caso, los demandantes, ministros de culto Testigos de Jehová, eran merecedores del mismo beneficio que se reconocía a los de otras confesiones consideradas «asociaciones religiosas» conforme a la legislación austriaca. A primera vista, parece que el Tribunal entiende que cualquier convicción religiosa constituye un fundamento válido para resultar liberado del servicio militar con independencia del status administrativo del que goce la confesión en la que se integre el sujeto, lo que supondría establecer una cierta conexión entre el art. 9 CEDH y la objeción de conciencia en relación a la fundamentación de esta última. Sin embargo, una lectura detallada del fallo permite ver que sus conclusiones no pueden separarse de las condiciones concretas del caso, que condicionan la decisión final de modo que se hace difícil considerar como generalizable esta línea argumental.

Por una parte, como se reconoce en la propia argumentación (par. 53 y 54 de Löffelmann, formulados de modo idéntico en las otras dos sentencias), la concreta confesión a la que pertenecen los demandantes sufrió previamente un trato discriminatorio en relación a su inscripción como sociedad religiosa en Austria que tuvo que ser remediada por el propio TEDH en 2008. Por ello, la equiparación que se realiza en estos casos resulta en una especie de extensión del remedio originalmente previsto en Religionsgemeinschaft der Zeugen Jehovas y Otros c. Austria. Pero además, la sentencia otorga una especial importancia al hecho de que los demandantes no sean ciudadanos corrientes, sino ministros de culto, presentándolo como el factor determinante, y podría decirse único, para poder recurrir al art. $9 \mathrm{CEDH}$ en la medida en que el privilegio de acceso a la objeción de conciencia que se les concede obedece a «asegurar el adecuado funcionamiento de los grupos religiosos en su dimensión colectiva, con lo que se promueve un objetivo protegido por el art. 9 del Convenio» (par. 48 Löffelmann) ${ }^{59}$. En sentido contrario, cabría pensar que, de otra manera, posiblemente este precepto no sería aplicable al caso.

Teniendo en cuenta esto último se puede comprender el aparente paso atrás que da el Tribunal en Koppi c. Austria unos meses después ${ }^{60}$. En este fallo se llega a la conclusión de que no existe vulneración del art. $14 \mathrm{CEDH}$ en relación con el art.

57 Brett y Townhead 2011, 97.

58 Löffelmann c. Austria, no 42967/98, 12 de marzo de 2009; Gütl c. Austria, n 49686/99, 12 de marzo de 2009; Lang c. Austria, n ${ }^{\circ}$ 28648/03, 19 de marzo de 2009.

59 Previamente, en el par. 47, el Tribunal realza la labor de los ministros de culto, considerándola especialmente significativa en relación a la dimensión colectiva de la libertad religiosa que se manifiesta a través de los grupos organizados que, al ser indispensables para el pluralismo en una sociedad democrática, encuentran protección en el núcleo del art. 9 CEDH.

60 Koppi c. Austria, no 33001/03, 10 de diciembre de 2009. 
9 por no permitir a un ministro de una confesión distinta a los Testigos de Jehová, que además no está reconocida como asociación religiosa en el país, liberarse de la prestación sustitutoria tras haber sido declarado objetor, tal y como se hace en Austria con los pertenecientes a aquellas que sí lo están. Sin mayores argumentos, y refiriéndose en todo momento a la legislación estatal como parámetro de enjuiciamiento, el Tribunal determina que el demandante no se encuentra en una situación particularmente similar o análoga a la de los miembros de las asociaciones religiosas. Posiblemente, el Tribunal no quiso traspasar la delicada y comprometida línea que suponía ligar de alguna manera al CEDH la posibilidad de la exención total, y no sólo a la prestación militar estrictamente, por razón de las propias convicciones, incluso a pesar de la teóricamente privilegiada situación del sujeto.

\section{El cambio doctrinal y la subsunción de la objeción de conciencia en el art. 9 CEDH}

El punto de inflexión, y el inicio de la que podría definirse como la tercera etapa en la evolución de la doctrina del TEDH sobre la objeción de conciencia, es la sentencia de la Gran Sala en el caso Bayatyan c. Armenia en julio de $2011^{61}$. Existe algún pronunciamiento inmediatamente anterior, que se menciona en el capítulo siguiente, donde ya parece intuirse una nueva perspectiva en la consideración del Tribunal hacia este fenómeno, pero este fallo es el primero en el que de manera explícita y directa se afirma que el rechazo a un deber jurídico por razones morales constituye una facultad de la libertad de pensamiento, conciencia y religión.

Inicialmente, la Sección Tercera del Tribunal consideró infundada la petición del demandante, condenado por negarse a realizar el servicio militar en un momento en el que la legislación nacional de su país (Armenia) todavía no reconocía la posibilidad de objetar en conciencia a cambio de realizar un servicio alternativo. Siguiendo con las bases de la jurisprudencia precedente, el fallo de instancia negó expresamente que el art. $9 \mathrm{CEDH}$ garantizara el derecho a la objeción de conciencia (par. 60), por lo que las autoridades nacionales no habrían vulnerado derecho alguno del sujeto al condenarle a pesar de que éste actuara motivado por auténticas convicciones religiosas (par. 64). La doctrina ha identificado el germen del cambio de perspectiva que más adelante operaría la Gran Sala en el voto disidente emitido por la Magistrada Ann Power a esta sentencia ${ }^{62}$, donde recurre a la jurisprudencia precedente y a los pronunciamientos de los órganos políticos del Consejo de Europa para defender una interpretación del $\mathrm{CEDH}$ como «instrumento vivo» cuyo art. 4.3 «ni reconoce ni excluye un derecho a la objeción de conciencia», lo cual, entiende la Magistrada, no significa que aquellos Estados que no lo contemplan adquieran carta blanca en relación a cómo tratan a quienes la invoquen, en la medida en que la fuerza vinculante del art. 9.1 CEDH sólo permite interferir en la libertad para manifestar la propia religión o credo cuando sea justificadamente necesario para proteger el interés público, del que no forma parte la seguridad nacional (par. 6).

61 Bayatyan c. Armenia [GS], n 23459/03, 7 de julio de 2011. Antes, la Sección Tercera emitió su sentencia el 3 de octubre de 2009.

62 Vid. Cañamares Arribas 2014, 46. 
Asumiendo esta idea, la Gran Sala determinó que, ante una demanda como la presentada, el art. 9 CEDH debía constituir, y esto es la principal novedad del fallo, el parámetro exclusivo de enjuiciamiento, sin ponerlo en relación ni con el 4.3 ni con cualquier otro (par. 109). Y ello es así porque, si bien es cierto que el art. 9 CEDH no menciona expresamente la objeción de conciencia, sí ampararía «la oposición al servicio militar cuando está motivada por un serio e insalvable conflicto entre la obligación de servir en el ejército y la conciencia personal o el mantenimiento de creencias profundas y genuinas, religiosas o de otro tipo», ya que entonces se estaría ante lo que "constituye una convicción o creencia con suficiente fuerza, seriedad, cohesión e importancia como para atraer las garantías del art. 9» (par. 110). La seriedad e importancia de las convicciones se presenta como el primer elemento determinante para acotar el alcance de la protección ya que, en sentido contrario, el Convenio no puede dar cobertura a cualquier actuación basada o motivada por las propias ideas, aunque se quiera plantear bajo la pátina de la objeción de conciencia ${ }^{63}$.

Junto a esto, se destaca la necesidad de considerar las circunstancias concretas del caso. Y el hecho de que, durante el iter procesal, Armenia hubiera regulado la objeción de conciencia militar estableciendo una amnistía para los condenados por ella obviamente influyó en la decisión. Así, se concluyó que el encarcelamiento del recurrente por rechazar el servicio de armas constituía «una injerencia que no era necesaria en una sociedad democrática en los términos del art. 9 del Convenio» (par. 128) ya que la imposición de una pena a un sujeto «en circunstancias en las que no existen concesiones para las exigencias de su conciencia y creencias, no puede ser considerada una medida necesaria en una sociedad democrática», especialmente si se tiene en cuenta que existen «alternativas viables y efectivas capaces de acomodar los intereses concurrentes, como demuestra la experiencia de la inmensa mayoría de los Estados europeos» (par. 124).

La existencia de un consenso entre los países europeos, idea equiparable a la noción de «tradición constitucional común» que emplea el Derecho Comunitario, parece determinante en el cambio de perspectiva del Tribunal. La idea de que el Convenio «es un instrumento vivo que (...) debe ser interpretado a la luz de las condiciones presentes $\rangle^{64}$, le permite alterar su jurisprudencia en lo relativo a la determinación del contenido de un derecho en función de las condiciones presentes en el contexto europeo y de la existencia de consenso o standard consolidado al respecto en el ámbito de los Estados miembros ${ }^{65}$. Y en este caso, frente a lo que sucedía décadas atrás, ahora existen enormes similitudes entre casi todos los Estados miembros en cuanto al reconocimiento de una prestación alternativa al servicio militar para

63 Así se estableció previamente en Pretty c. Reino Unido, no 2346/02, 29 de abril de 2002, par. 82. Ahora bien, la Gran Sala no termina de establecer en términos jurídicos cuál es la diferencia entre el supuesto de esta sentencia (eutanasia activa) y el presente para decidir que uno está cubierto por el art. 9 CEDH y el otro no, pues en ambos casos la motivación del acto es una creencia seria y no hay previsión expresa en el Convenio. En el fondo, la única diferencia es la existencia de un mayor acuerdo entre los países miembros en lo que respecta a la objeción de conciencia militar que no se da en relación a la aceptación de la eutanasia activa. En el mismo sentido, y más próxima cronológicamente al fallo comentado, en Skugar y Otros c. Rusia (Dec.), no 40010/04, 3 de diciembre de 2009, se afirma que aquellos actos que no son una expresión directa de las propias convicciones ni suponen la materialización de un mandato moral están fuera de la protección del art. 9.1 CEDH, especialmente si contradicen normas ideológicamente neutras.

${ }_{64}$ Esta premisa, consolidada ya en la jurisprudencia del TEDH, fue inicialmente planteada en la Sentencia Tyrer c. Reino Unido, 25 de abril de 1978.

65 López Guerra 2013-2, 179. 
quienes planteen reservas de conciencia a éste, por lo que las circunstancias ya no son las mismas que en el pasado justificaron una doctrina más restrictiva, al menos en lo que se refiere a este supuesto en particular.

Siendo realistas, ésta es la principal razón que lleva a la Gran Sala del Tribunal a entender que aquellos Estados que no hayan reconocido la objeción de conciencia «disfrutan sólo de un limitado margen de apreciación» en cuanto a las posibilidades que pueden prever sus normas (par. 123). De hecho, considerando que no permitir el ejercicio de este derecho es una limitación de la libertad de pensamiento del art. 9 $\mathrm{CEDH}$, deben existir razones convincentes y apremiantes para ello y, en particular, una «necesidad social acuciante».

Estos mismos argumentos han sido empleados posteriormente por el Tribunal en los fallos Erçep c. Turquía, donde además se menciona la importancia del reconocimiento de la objeción de conciencia como instrumento para articular el pluralismo social y los derechos de los grupos religiosos minoritarios, Bukharatyan c. Armenia, Tsaturyan c. Armenia, Feti Demirtaş c. Turquía, o Buldu y Otros c. Turquía ${ }^{66}$. Con ellas se consolida la nueva línea doctrinal, que soluciona los casos de objeción de conciencia valorándolos como una exteriorización de las propias convicciones y, por tanto, desde el punto de vista de la legitimidad de las posibles restricciones que se impongan por parte del poder público a esta facultad, que sí está expresamente vinculada al art. 9.1 CEDH. Ahora bien, entre decir esto y afirmar que se está dando carta de libertad a un derecho subjetivo general o ilimitado para rechazar mandatos jurídicos sin importar las consecuencias hay una distancia enorme.

En primer lugar, porque el Tribunal en Bayatyan es muy claro en afirmar que solamente si concurren auténticas y profundas convicciones y éstas son incompatibles de manera absoluta con el deber problemático, la pretensión del sujeto podrá encontrar cabida en el art. 9 CEDH. Cualquier otra motivación, o incluso una menor intensidad del conflicto de conciencia, desligaría la pretensión de la protección dispensada por el Convenio. Lo que resulta indiferente es la naturaleza de las ideas o creencias alegadas. Aunque las de tipo religioso parecen concebirse como el paradigma de convicción profunda susceptible de motivar un conflicto irresoluble para el sujeto de la obligación, el propio fallo equipara a éstas aquellas de otro tipo que sean equivalentes. Esta idea se reitera de modo más evidente en la posterior sentencia Savda c. Turquía, de $2012^{67}$, en la que se acepta expresamente la demanda de un pretendido objetor que basaba su negativa al servicio militar en convicciones de tipo pacifista.

Este último pronunciamiento, además, muestra una cierta evolución en el sentido de acotar el margen de apreciación estatal en relación a la objeción de conciencia militar $^{68}$. El Tribunal declara extensible, mutandis mutandis, a este derecho la obligación que recae sobre los Estados para garantizar del derecho a la vida privada del art. $8 \mathrm{CEDH}$, referida a la previsión de un procedimiento efectivo y accesible destinado a protegerlo (par. 98) que permita valorar las solicitudes de los sujetos. Por tanto, parece que la libertad de los Estados no sólo se limita en relación a la imposición de sanciones. La inclusión de la objeción de conciencia en el art. 9 CEDH

\footnotetext{
66 Erçep c. Turquía, no 43965/04, 22 de noviembre de 2011; Bukharatyan c. Armenia, $\mathrm{n}^{\circ}$ 37819/03, 10 de enero de 2012; Tsaturyan c. Armenia, no 37821/03, 10 de enero de 2012; Feti Demirtaş c. Turquía, no 5260/07, 17 de enero de 2012; Buldu y Otros c. Turquía, nº 14017/08, 3 de junio de 2014.

67 Savda c. Turquía, $\mathrm{n}^{\circ}$ 42730/05, 12 de junio de 2012.

68 Que inmediatamente se reiteraría en Tarhan c. Turquía, n 9078/06, 17 de julio de 2012.
} 
implicaría también un deber positivo para las autoridades nacionales de regular e implementar un procedimiento administrativo que permita valorar las pretensiones de los sujetos al respecto y acceder a una alternativa en caso de ser admitidas, ya que de lo contrario se estaría ante un sistema en el que no se logra «un justo equilibrio entre el interés de la sociedad en su conjunto y el de los objetores de conciencia» (par. 100, aunque la idea ya había aparecido antes en Erçep).

Por otro lado, en cada uno de estos casos, al valorar la legitimidad y la necesidad de la limitación del derecho de los objetores el Tribunal está realizando una ponderación entre los bienes y derechos presentes en los términos del punto 2 del art. $9 \mathrm{CEDH}$, algo obvio en la medida en que se ha caracterizado a la objeción de conciencia como una exteriorización de la libertad de pensamiento, conciencia y religión. Como tal, estará sometida a aquellas restricciones que, previstas por ley, constituyan medidas necesarias, en una sociedad democrática, para garantizar la seguridad pública, el orden, la salud o la moral públicas, o los derechos y las libertades de los demás. La protección de estos bienes jurídicos puede justificar una modulación proporcionada y justificada de la objeción de conciencia por parte del Legislador nacional al reconocerla, o del órgano administrativo encargado de su valoración al ser planteada en cada caso. Ciertamente, al TEDH le resulta complicado encontrar un derecho o valor de suficiente entidad como para restringir el derecho de los objetores en el supuesto del servicio militar. Sin embargo, como se verá a continuación, en otras situaciones donde puede surgir un conflicto real, especialmente con derechos de terceros, el Tribunal sí ha considerado, y validado, esa posibilidad en función del grado de inocuidad que revista la actuación del objetor sobre el orden público.

\section{Los límites del derecho y la ponderación de intereses concurrentes}

El cambio en el canon de análisis de la objeción de conciencia al servicio militar que opera la sentencia Bayatyan abre para el TEDH la posibilidad de enjuiciar, de manera directa a partir únicamente del art. $9 \mathrm{CEDH}$, la viabilidad de su invocación en otros supuestos distintos no reconocidos por un determinado ordenamiento nacional o más allá de las condiciones impuestas por las normas reguladoras. Esto es así porque de la misma se puede extrapolar una regla general que es potencialmente aplicable a cualquier otro sector de la realidad: todo caso de objeción de conciencia deberá ser tratado como una exteriorización de las propias convicciones cuya cobertura por parte de la libertad de pensamiento estará condicionada por los límites del apartado 2 del art. 9 CEDH. Lejos de ampliar el alcance del derecho, esto supone introducir la posibilidad de condicionar o restringir su ejercicio de manera proporcionada y cuando sea necesario en una sociedad democrática para salvaguardar determinados bienes jurídicos o los derechos de terceros. Con ello se pone de manifiesto que este fenómeno debe ser abordado en relación a las circunstancias que lo acompañan y sobre las que proyecta inevitablemente ciertas consecuencias, debiendo tenerlas en cuenta al resolver cada caso concreto.

Aunque cabe esperar que con el tiempo vaya habiendo más sentencias relativas a otros supuestos de rechazo moral a obligaciones jurídicas en las que la argumentación se estructure de esta manera, a día de hoy el TEDH sólo ha tenido ocasión de emplear esta doctrina en un caso distinto al servicio militar, el asunto Eweida y 
Otros c. Reino Unido, de $2013^{69}$, donde llega a una conclusión bastante diferente a la defendida en 2011. Ciertamente, en esta última controversia se plantea un problema de discriminación en la prestación de un servicio de carácter o, al menos, cierta relevancia pública, que evidentemente condiciona el sentido de la solución. Pero justamente por esto el fallo permite ver cómo opera esta nueva doctrina del TEDH cuando el ejercicio, en principio legítimo, de la objeción de conciencia genera un perjuicio sobre bienes jurídicos concretos e identificables de terceros, cosa que no sucedía en las controversias relativas al servicio militar.

Además de en ésta, la cuestión de la objeción de conciencia se ha tocado tangencialmente en sentencias más recientes relativas a la interrupción del embarazo, mostrando que no sólo se trata de un problema de derechos y límites. En los casos R. R. c. Polonia, anterior en muy poco tiempo a Bayatyan, y P. y S. c. Polonia, de $2012^{70}$, se contienen obiter dictum, algunas consideraciones sobre cómo debe afrontar el poder público el problema del personal sanitario que rechaza, por razones morales, la obligación de practicar o participar en intervenciones de interrupción del embarazo legales que deriva de su adscripción. En estas sentencias no se resuelve ni se plantea en ningún momento pretensión alguna relacionada con el art. 9 CEDH, pero el Tribunal no deja pasar la ocasión de afirmar que «los Estados están obligados a organizar su sistema sanitario de modo que se garantice que el ejercicio efectivo de la libertad de conciencia de los profesionales de la salud en el contexto de sus funciones no impide a los pacientes acceder a aquellos servicios a los que tienen derecho en virtud de la legislación aplicable» (R. R., par. 206; P. y S., par. 106). Esta idea se acompaña de una referencia a la doctrina de Pichon y Sajous que deja entrever que, aunque la actuación de los profesionales sanitarios pueda constituir un ejercicio legítimo de su libertad de pensamiento, conciencia y religión, no sería admisible una situación en la que suponga una imposición de las propias convicciones sobre las de quien demanda la prestación sanitaria.

Por tanto, aunque la objeción de conciencia del personal sanitario pueda estar amparada en última instancia por el art. $9 \mathrm{CEDH}$ (que es algo que ni se niega ni se afirma), la efectividad de su invocación para rechazar las obligaciones propias del puesto estará condicionada por la correcta satisfacción del derecho de los pacientes y usuarios de los servicios a acceder a aquellas prestaciones jurídicamente establecidas. En caso de llegar a una situación de conflicto, aplicando la lógica del Tribunal, la admisibilidad de la pretensión de objetar del facultativo dependerá en buena medida de cómo el poder público haya organizado su sistema sanitario para conciliar ambos intereses y de la capacidad de la Administración para responder de manera efectiva a la demanda del paciente en caso de liberar del deber al profesional que muestra reservas de conciencia.

Hay que tener en cuenta que la visión del TEDH sobre este supuesto de objeción de conciencia está íntimamente ligada a la doctrina sobre el acceso a la interrupción del embarazo que desarrolla en las sentencias citadas y, previamente, en Tysiac c. Polonia, de $2007^{71}$, que se puede sintetizar como sigue: si bien no existe en el CEDH un derecho de las mujeres a interrumpir su embarazo que implique una obligación para los Estados de reconocer esta posibilidad o de adoptar un modelo concreto de

\footnotetext{
69 Eweida y Otros c. Reino Unido, $\mathrm{n}^{\circ}$ 48420/10, 59842/10, 51671/10 y 36516/10, 15 de enero de 2013.

70 R. R. c. Polonia, $\mathrm{n}^{\circ}$ 27617/04, 26 de mayo de 2011; P. y S. c. Polonia, $\mathrm{n}^{\circ}$ 57375/08, 30 de octubre de 2012.

71 Tysiac c. Polonia, no 5410/03, 20 de marzo 2007.
} 
despenalización, en el momento en el que efectivamente alguno decida hacerlo, su sistema sanitario debe permitir el acceso real a esta prestación en los términos establecidos por la legislación nacional, sin impedimentos normativos o fácticos subrepticios; de lo contrario, se produciría una lesión del derecho de las mujeres al respeto de su vida privada y familiar amparado por el art. $8 \mathrm{CEDH}$.

Todo esto viene a reconocer la importancia de contar con un procedimiento reglado para articular el ejercicio de la objeción de conciencia de los empleados públicos y de aquellos sujetos cuyos deberes profesionales cumplen la misión de satisfacer derechos de terceros. Todo con el fin de conciliar los intereses concurrentes sin tener que recurrir al inevitable sacrificio que se derivaría de su oposición en un juicio de ponderación, donde la objeción de conciencia, aunque se considere una opción legítima amparada por el art. $9 \mathrm{CEDH}$, no es inmune a posibles restricciones justificadas, especialmente para salvaguardar los derechos de los demás. Muestra de ello es el razonamiento de la sentencia Eweida, en el que, entre otras cuestiones relativas al derecho a portar simbología religiosa, se plantea la viabilidad de dos casos de objeción de conciencia: el de una empleada pública ante el deber de tramitar uniones civiles entre personas del mismo sexo y el de un trabajador de una empresa privada respecto del deber laboral de prestar asesoramiento psico-sexual a parejas homosexuales.

En el primer caso, planteado como una posible discriminación por motivos religiosos, el Tribunal se apoya nuevamente en el juego de los arts. 9 y $14 \mathrm{CEDH}$ para valorar si la negativa de las autoridades a eximir a la demandante de su labor fue adecuada y proporcionada en los términos del principio de igualdad. No obstante, reconoce que, a pesar de la aplicabilidad del art. 14, «los hechos en cuestión entraban dentro del ámbito del artículo 9» (par. 103), enjuiciando, en la práctica, la restricción de la libertad de pensamiento, conciencia y religión de la afectada (que se califica como «particularmente perjudicial») a partir de su proporcionalidad y de la finalidad a la que obedece. Considerando que la obligación que se pretendía rechazar responde a la realización de un objetivo legítimo relacionado con la no discriminación por razón de sexo y la igualdad de oportunidades (par. 105), el Tribunal concluye que la limitación absoluta del derecho a la objeción de conciencia resulta proporcionada como medio para asegurar «los derechos de los demás que también están protegidos por el Convenio», por lo que al actuar así, y a pesar del perjuicio evidente que supone para la recurrente, las autoridades nacionales no superaron el margen de apreciación del que gozan en estas circunstancias (par. 106).

Esta conclusión no sólo no altera sino que confirma la idea que subyace en las últimas sentencias del TEDH sobre objeción de conciencia militar: si entran en conflicto, se debe realizar una ponderación entre derechos recogidos en el Convenio cuyo resultado bien puede ser el sacrificio de la libertad de pensamiento de un sujeto. En este caso, además, se añade que permitir el ejercicio de esta última supondría dar carta blanca a una actuación discriminatoria hacia otras personas por razón de su orientación sexual que, para mayor gravedad, se realizaría en nombre de una autoridad pública cuyo compromiso con la igualdad se relativizaría ante las convicciones privadas de uno de sus empleados.

En cuanto al segundo caso, cuando se trata de obligaciones derivadas de un vínculo laboral, de tipo privado, también existe una obligación para el Estado de garantizar el derecho de objeción de conciencia de los ciudadanos como manifestación del art. 9 CEDH cuando concurra un fundamento relevante para ello (par. 108). Pero, 
nuevamente, el Tribunal niega que ésta pueda ser válidamente ejercida cuando con ello se afectan derechos de terceros, considerando legítimo el despido del demandante por parte de su empleador en relación a las obligaciones que impone el Convenio. Aunque el Tribunal no considera que «la firma de un contrato de trabajo y la asunción de responsabilidades que conlleva tenga un impacto en su libertad a manifestar sus creencias religiosas», el hecho de que el sujeto conociera previamente y asumiera voluntariamente la obligación que pretende rechazar sí debe ser tenido en cuenta en la ponderación («justo equilibrio», en términos del fallo), que se desnivela definitivamente en favor de la posición del empleador porque la intención de éste es «garantizar la aplicación de su política de brindar un servicio sin discriminación»a través de sus trabajadores, contribuyendo con ello a satisfacer los derechos de terceros (par. 109). Por tanto, también en este caso el derecho de objeción de conciencia, que se reconoce en cuanto a su existencia, sufre una limitación absoluta con el fin de preservar derechos ajenos y la consecución de un valor esencial en una sociedad democrática como es la interdicción de toda discriminación.

Todo lo expuesto echa por tierra la idea de que el TEDH configurara en Bayatyan un derecho general de amplio alcance de los ciudadanos a obtener la exención de aquellas obligaciones jurídicas que chocan con sus convicciones profundas. Al contrario, una lectura conjunta de la jurisprudencia desarrollada desde entonces muestra que se trata de una manifestación de la libertad de pensamiento particularmente vulnerable a restricciones desde el momento en el que interfiera con derechos ajenos o intereses sociales relevantes en clave del Convenio. Por ello, a pesar de su inclusión en el art. 9 el margen de apreciación de los Estados para regular esta cuestión conforme a sus propios parámetros sigue siendo amplio; lo único que parece vetado es negar el ejercicio de la objeción de conciencia en aquellos casos en los que no tenga impacto alguno en un interés relevante, bien jurídico o derecho. En cualquier caso, no hay que olvidar el temor del Tribunal a establecer afirmaciones contundentes cuando no existe un consenso europeo en la materia; sería ingenuo pensar que la ausencia de similitudes claras entre las legislaciones de los Estados miembros cuando abordan supuestos de objeción de conciencia distintos al militar no ha tenido influencia en estas decisiones.

\section{Conclusiones}

Mientras que la Asamblea Parlamentaria ha evolucionado en sus planteamientos sobre la objeción de conciencia al servicio militar desde una visión muy abierta, y adelantada a su tiempo, hasta otra más pragmática y práctica, alineada con la idea de intervención mínima del Comité de Ministros, el Tribunal de Estrasburgo parece haber seguido un camino en parte contrario. Desde una perspectiva siempre más comedida, le ha costado reconocer el anclaje de este derecho en el Convenio, seguramente lastrado hasta tiempos recientes por la ausencia de ese consenso entre los Estados miembros al que siempre recurre para resolver el fondo de las controversias relacionadas con el art. 9 del mismo. De hecho, da la impresión de que en estas cuestiones tienen más peso las razones de similitud jurídica entre ordenamientos que las de justicia.

En cualquier caso, una vez que el Tribunal ha optado por considerar la objeción de conciencia como una manifestación de la libertad de pensamiento, conciencia y religión protegida, un análisis conjunto de la jurisprudencia más reciente mues- 
tra como su tratamiento es, a todos los efectos, el de una proyección externa de la misma. Así, la legitimidad de su ejercicio o, dicho de otro modo, la capacidad de los Estados para modularlo, deberá valorarse en relación a los límites establecidos en el apartado 2 del art. $9 \mathrm{CEDH}$, especialmente la afectación de los derechos de los demás, que se erige como el principal factor restrictivo.

La premisa en la jurisprudencia del TEDH es que los Estados podrán, conforme a sus propios criterios, negar a sus ciudadanos la posibilidad de rechazar por razones de conciencia un determinado deber jurídico cuando con ello se persiga una finalidad legítima y se trate de una medida necesaria en una sociedad democrática para garantizar los derechos e intereses concurrentes garantizados por la Convención. Por este motivo, en la escasa jurisprudencia dictada desde que se operó el cambio doctrinal, la negativa a presar el servicio de armas se ha visto especialmente privilegiada. El Tribunal no ha encontrado en este supuesto un valor jurídico relevante que se vea afectado por el ejercicio de la objeción de conciencia en tal grado que justifique su restricción, al contrario de lo que sucedería en muchos otros casos, especialmente cuando quienes pretenden sustraerse de sus deberes son empleados públicos. Tanto en Bayatyan como en Eweida, las dos sentencias de referencia, la doctrina que se aplica es exactamente la misma, lo que varía es el resultado de la ponderación, porque en el primer caso el hecho de liberar al sujeto del deber problemático no tiene consecuencias concretas sobre la esfera jurídica de terceros mientras que en el segundo sí. Dicho de otro modo, cuando el ejercicio de la objeción de conciencia resulta inocuo en relación al orden público protegido por la ley y los derechos de terceros, como sucede en el servicio militar, el Tribunal no encuentra razón que justifique su restricción; sin embargo, cuando pueda implicar una lesión de los mismos la legitimidad de la pretensión del objetor dependerá del resultado de un juicio de ponderación que permita valorar la adecuación de la restricción operada por los Estados como garantes directos de los derechos de todos los ciudadanos.

Por todo ello, es un error pensar que, al vincularlo con el art. $9 \mathrm{CEDH}$, el Tribunal de Estrasburgo esté abriendo la puerta a un derecho a la objeción de conciencia de carácter ilimitado o privilegiado que deba ser aceptado en todo caso o condición sin importar el contexto. Todo lo contrario. Lo está configurando como una facultad subjetiva que cede muy fácilmente ante cualquier otro bien jurídico con el que entre en conflicto. Con ello se consigue caracterizar la objeción de conciencia como lo que realmente es en cualquiera de sus supuestos: una excepción puntual en el normal funcionamiento de un sistema jurídico.

\section{Bibliografía}

F. Amérigo Cuervo-Arango, «Objeción de conciencia al servicio militar», Anuario de Derechos Humanos 3 (1985) 11-47.

F. Arlettaz, «La jurisprudencia del Tribunal Europeo de Derechos Humanos sobre la libertad religiosa: un análisis jurídico-político», Derechos y Libertades 27 (2012) 209-240.

L. Brett; L. Townhead, «Conscientious objection to military service», G. Gilbert; F. Hampson; C. Sandoval (Eds.), Strategic Visions for Human Rights: Essays in Honour of Professor Kevin Boyle, New York, 2011, 91-107.

S. Cañamares Arribas, «La evolución de la doctrina del Tribunal Europeo de Derechos Humanos en materia de objeción de conciencia», Revista de Derecho Público 46 (2014) 37-58. 
J.P. Cattelain, La objeción de conciencia, Barcelona, 1973.

C. Jerez Delgado; M.V. Madero Jiménez, «Objeción de conciencia y equilibrio». Revista Jurídica de la Universidad Autónoma de Madrid 28 (2013) 161-176.

L. López Guerra, «El diálogo entre el Tribunal Europeo de Derechos Humanos y los Tribunales españoles. Coincidencias y divergencias», Teoría y Realidad Constitucional 32 (2013) 139-158.

L. López Guerra, «El sistema europeo de protección de Derechos Humanos», G.R. Bandeira; R. Ureña; A. Torres (Coords.), Protección Multinivel de Derechos Humanos, Barcelona, 2013, 165-186.

J. Martínez Torrón, «Los límites a la libertad de religión y de creencia en el Convenio Europeo de Derechos Humanos», Revista General de Derecho Canónico y de Derecho Eclesiástico del Estado 2 (2003) 1-46.

C.C. Moskos; J.W. Chambers II, «The secularization of conscience reconsidered», C.C. Moskos; J.W. Chambers II (Eds.), The new conscientious objection. From sacred to secular resistance, New York, 1993, 196-208.

F. Navarro Aznar, «La objeción de conciencia al servicio militar en la perspectiva del pacifismo», A. Martínez; M. López (Eds.), La objeción de conciencia en el Derecho español e italiano, Murcia, 1990, 163-186.

R. Navarro-Valls; J. Martínez Torrón, Conflictos entre conciencia y ley. Las objeciones de conciencia, Madrid, $2012^{2}$.

J. Oliver Araujo, La objeción de conciencia al servicio militar, Madrid, 1993.

J. Rivero, Les libertés publiques 2, Paris, $1997^{6}$.

P. Rowe, The Impact of Human Rights Law on Armed Forces, Cambridge, 2006.

F.J. Ruiz Bursón, «Novedades desde Estrasburgo sobre la objeción de conciencia». Revista General de Derecho Canónico y de Derecho Eclesiástico del Estado 31 (2013) 1-27.

A. Sainz Arnaiz, La apertura constitucional al Derecho Internacional y Europeo de los derechos humanos. El artículo 10.2 de la Constitución española, Madrid, 1999.

J.A. Xiol Ríos, «La libertad ideológica o libertad de conciencia», La libertad ideológica. Actas de las VI Jornadas de la Asociación de Letrados del Tribunal Constitucional, Madrid, 2001, 15-80. 